\title{
Application and Analysis of Biological Electrospray in Tissue Engineering
}

\author{
Ma Yunmin, Liu Yuanyuan", Chen Haiping and Hu Qingxi
}

Rapid Manufacturing Engineering Center, Shanghai University, Shanghai, 200444, P.R. China

\begin{abstract}
Nanofiber scaffolds are suitable tools in tissue engineering. Electro spinning materials together with cells are not adequate to obtain a high cellular zing tissue construct as the shear force, tensile force, and other physical effects excited in the electro spinning process, which are harmful to cellular differentiation, development and function. However, this limitation has been overcome by a micro integration system containing bio-electro spraying human adipose stem cells (ASCs) and electro spinning Polyvinyl alcohol (PVA). Then, it was compared to the single electro spinning nanofiber scaffolds in relation to cell viability, which showed that the scaffolds through micro integration approach showed a larger number of surviving cells and is more suitable for cell growth and proliferation. In addition, the relationship between different parameters of biological electrospray (voltage, flow rate and distance of the needle from the collecting board) and droplet size of cell suspension was elucidated and the droplets with a near-mono distribution $(<50 \mathrm{um})$ could be generated to deposit a single living cell within a droplet. The association of bio-electro spraying with electro spinning (a scaffold preparation technique) has been demonstrated to be a promising and suitable tissue engineering approach in producing nanofiber based three-dimensional (3-D) cell seeded scaffolds.
\end{abstract}

Keywords: Bio-electro spraying, Micro integration, Electro spinning, Tissue engineering scaffold.

\section{INTRODUCTION}

The current method of tissue engineering is separate continuous techniques of scaffold fabrication and subsequent cell seeding, i.e. after a period of culture in vitro, implant the scaffolds into body to repair and reconstruct the defected tissue and organs. Such approaches are facing the limitation of non-uniform cell colonization, and the contact surface between scaffolds and cells is too small that making the cells in an unbalanced material and energy exchange environment, which reduced cell infiltration [1].

The process of electro spinning that permits generation of nanofibers and scaffolds in large quantities that resemble the scale and fibrous nature of the native ECM, has recently experienced renewed interest for tissue engineering and regenerative medicine applications [2-5]. Through electro spun scaffold materials together with cells, the problem of poor cell infiltration was solved to some extent, and the nanofibers have provided the cells with a bionic microenvironment. However, most electro spun cells died due to the tensile force, shearing force and other harmful forces generated from spinning process in combination with the exposure of cells to some toxic organic solvents, with only a few cells survived [6].

In the endeavor to directly handle cells by means of jets, laser guided writing (LGW), ink-jet printing (IJP), pressure assisted/driven jetting, has impulsively confirmed this process and has achieved some notable goals [7]. However,

*Address correspondence to this author at the P.O. Box 113, Rapid Manufacturing Engineering Center, Shanghai University, Shanghai, 200444, P.R. China; Tel: 15900611572; E-mail: yuanyuan_liu@shu.edu.cn these studies have not affirmed the true live cell colonization [8]. In contrast, the bio-electrosprays has exploited a high intensity electric field driven process for the distribution of cell-containing droplets $[9,10]$.

Bio-electro spraying is one such non-contact direct jetbased methodology wherein a liquid medium is charged to several thousands of voltages and passed through a fine needle to be fragmented into micrometric droplets [11]. "Bio-electro spraying" a suspension of living cells can form micro-droplets of cells without causing any significant deleterious effects on treated cells at a molecular level and can generate fine micrometer sized cell-bearing droplets and process denser cell suspensions in comparison to those controls such as ink-jet printing and aerosol delivery [12-14]. However, the regulation of various parameters including voltage, flow rate, and distance of the needle from the collecting plate, as well as the influence of these parameters in relation to the droplet size of cell suspension have not yet been completely clarified.

In this paper, a micro integration approach of combining electro spinning and electrospray technology was put forward, which can not only prevent the cell damage from single electro spinning, but also the direct incorporation of living cells into nanoscaffolds during electro spinning process would promote cell infiltration and even distribution in the structure. In addition, the relationship between different parameters of bio-electro spraying and droplet size of cell suspension was also explored, with a view to further reducing the droplet size to deposit a single living cell within a droplet. 


\section{MATERIALS AND MATHODS}

\subsection{Material Preparation}

PVA (MW=2000) was dissolved in deionized water to prepare the $8.8 \%$ PVA electro spinning solution. The subculture Human adipose stem cells (ASCs) of second generation were trypsin zed, 1000r/min centrifugal for $5 \mathrm{~min}$ to prepare the cell suspension with a constant cell density of $4 \times 10^{6}$ cells $/ \mathrm{ml}$. $5 \mathrm{ml}$ of ASCs cell suspension were mixed into $20 \mathrm{ml}$ of $8.8 \%$ PVA solution, as single electro spinning material.

\subsection{Bio-Spraying ASCs Cells Concurrently with Electro Spinning PVA Solution}

As shown in Fig. (1), the micro integration technique is a side to side capillary configuration that is located $6 \mathrm{~cm}$ from the collecting plate. Using simultaneous approach to ensure an even distribution and high permeability of cells in nanofiber scaffolds. ASCs suspension was pushed into a sterile stainless steel needle tube (inside diameter is $0.6 \mathrm{~mm}$, charged at $24 \mathrm{KV}$ ) through sterile tubing with a precision pump at $250 \mu \mathrm{l} / \mathrm{min}$. At the same time, the PVA solution was forced at $20 \mu \mathrm{l} / \mathrm{min}$ into a capillary that charged at $12 \mathrm{KV}$. The collecting plate as the cathode (charged at $0 \mathrm{KV}$ ) was moving around on an $\mathrm{x}-\mathrm{y}$ motion platform at the speed of $10 \mathrm{~cm} / \mathrm{s}$. During the operation, a digital high-speed camera was used to observe the jetting process in real time.

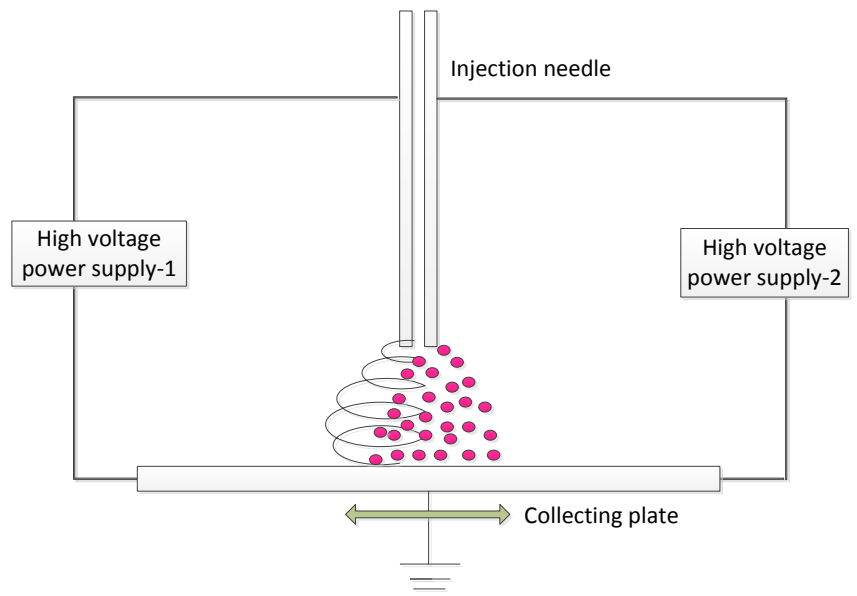

Fig. (1). Schematic of the micro integration system.

\subsection{Electro Spinning the Mixture of PVA and ASCs Cells}

The mixed solution of ASCs suspension and PVA solution was fed at $20 \mu \mathrm{l} / \mathrm{min}$ using a precision pump through sterile syringes into a sterile capillary.

\subsection{Viability and Proliferation of ASCs Cells}

\subsubsection{Evaluation of Cell Morphology by SEM}

The two scaffolds were washed with Phosphate buffer solution (PBS) for 2-3 times and then gradiently dehydrated with $25 \%, 50 \%, 75 \%, 85 \%, 95 \%, 100 \%$ alcohol solution in turns soaking for every five minutes, and gradient off alcohol using different ratios of ethanol/hex methyl diamine alkyl mixed solution (ethanol: hexamethyl diamine alkyl $=3: 1$, $1: 1,1: 3,0: 1)$ in sequence soaking for every ten minutes. Finally, observed the cell morphology on scaffold by scanning electron microscope (Zeiss Auriga crossbeam system, Germany).

\subsubsection{Live/Dead Staining Assay}

Cell viability was monitored using Laser scanning confocal microscope (LSM710) after adding $1 \mu$ l of staining A and $1 \mu \mathrm{l}$ of staining B on the scaffolds.

\subsubsection{Evaluation of Cell Proliferation-MTT}

Two samples were transferred into separate wells of a 6well culture plate (NUNC, Roskilde, Denmark), added the MEM medium and $40 \mu \mathrm{l}$ MTT solution $(5 \mathrm{mg} / \mathrm{ml}), 4$ hours later, carefully aspirated the supernatant and added $420 \mu \mathrm{l}$ DMSO. $100 \mathrm{ml}$ of liquid was transferred into separate wells of a 96-well culture plate to measure the absorbance values (OD Value) with enzyme-linked immunosorbent assay (wavelength of $492 \mathrm{~nm}$ ), recorded the results.

\subsection{Investigation of Factors that Affect the Droplet Size}

Droplet size, one of the most critical parameters of bioelectrospray, is largely determining the resolution and uniformity of cells on the scaffold.

The single cell suspension was electrosprayed and monitored through a biological microscope connected to a monitoring camera (WAT-502A Watec Co.Ltd, Kanagawa, Japan) to determine the parameter conditions of stable spray. The used method is adding transformer oil on the bottom of a glass dish, and collecting the droplets directly in the spray field during the generation of the film. The results were seen with a microscope followed by taking an average diameter. By allowing only one parameter to change with others remained fixed is used to explore the effect of this changing parameter to droplet diameter. Among them, the calculation formula of sauter mean diameter (SMD) is [15]:

$$
\mathrm{d}_{s}=\sum_{i=1}^{N} n_{i} d_{i}^{3} / \sum_{i=1}^{N} n_{i} d_{i}^{2}
$$

Where, $d_{s}$ is saunter mean droplet diameter; $\mathrm{N}$ is the number of all droplets seen; $\mathrm{n}_{\mathrm{i}}$ is the number of droplets corresponding to the diameter of $\mathrm{d}_{\mathrm{i}} .100$ of droplet diameter of each sample is read randomly before the data processing.

\section{RESULTS AND DISCUSSION}

\subsection{ASCs Viability and Morphology}

As shown in Fig. (2), the ASCs cells micro integrated PVA nanofibers could be well attached to the surface and pore inner walls of the scaffolds, fully extended, fusiform and presented typical human adipose stem cells morphology. Cell growth around the material also had no abnormal activity, and cell morphology wasn't changed or disturbed. ASCs Cells dispersed in the nanofibers, to some extent improved the resolution and uniformity of the scaffolds. While the viability of ASCs cells electro spun together with PVA are relatively rare, mostly rounded, and few cells had adipose stem cell morphology. Cell aggregation phenomenon was serious, uneven distribution, which caused the low resolution of scaffolds. 


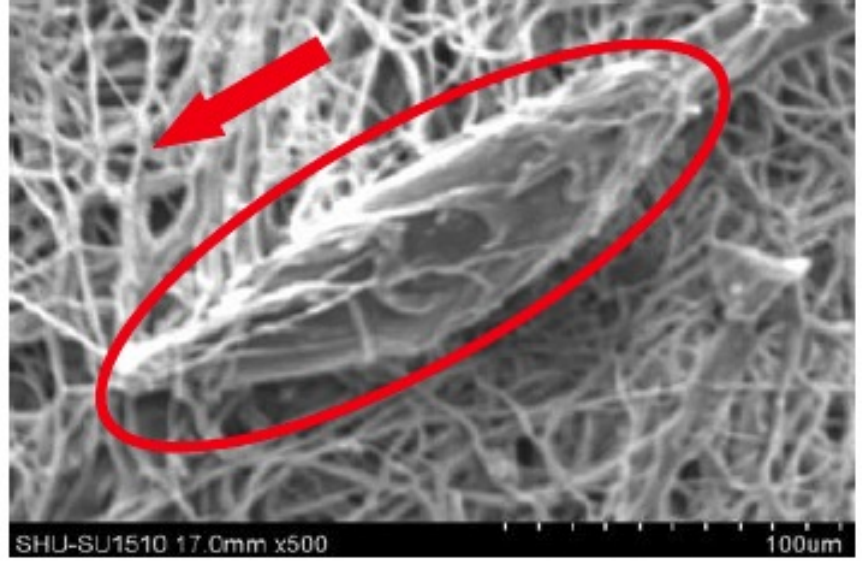

(A)

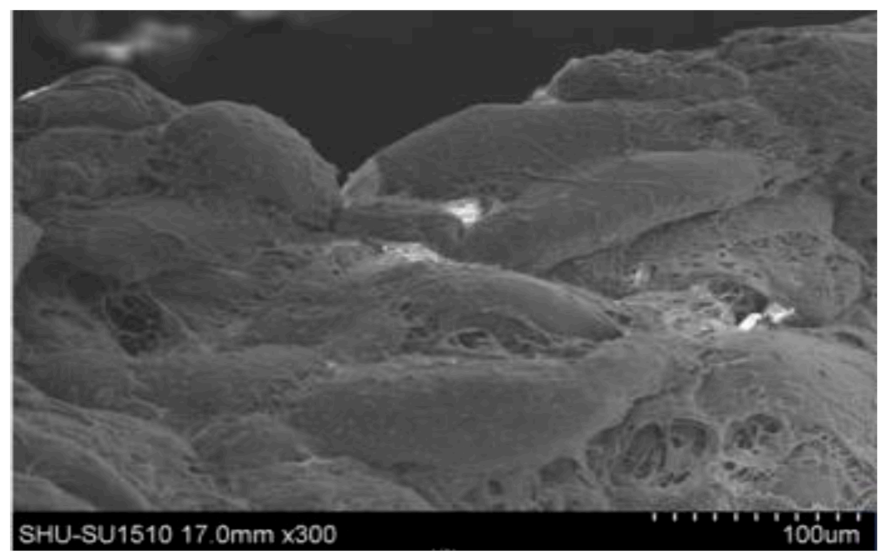

(C)

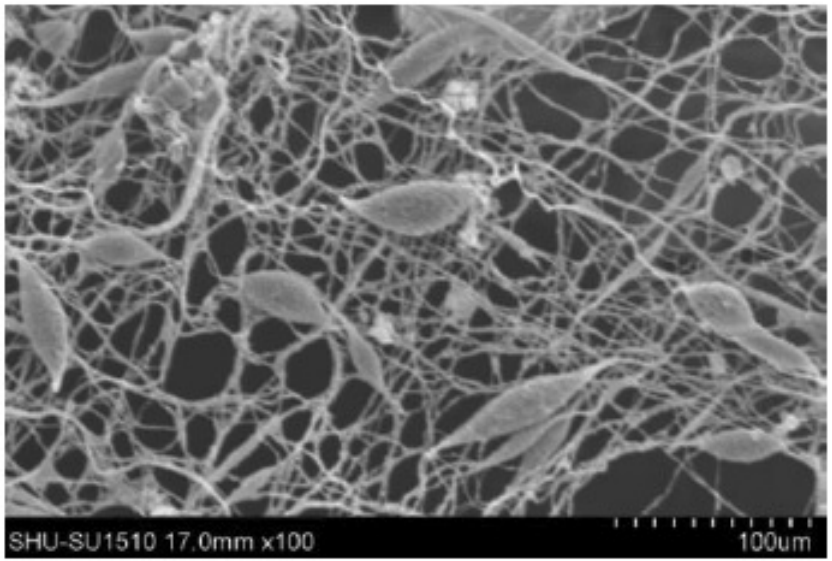

(B)

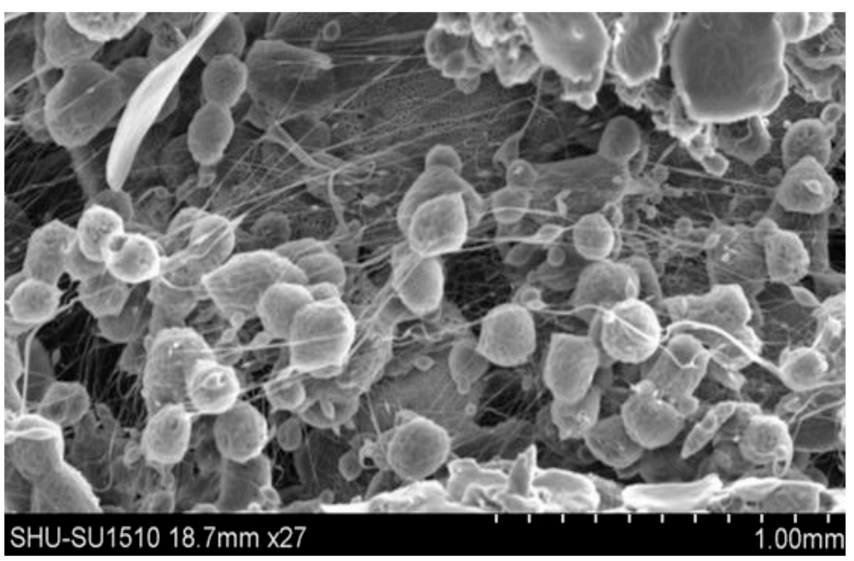

(D)

Fig. (2). Morphology of ASCs cells on nanofiber scaffolds after seven days of culture: (A, B) prepared by integrating method and (C, D) made by single electro spinning technique. Within the red borders was a single ASCs cell, and the red arrow was referring to the nanofiber scaffold.

In Fig. (3), most micro integrated ASCs seeded on the scaffolds survived while the viability of electro spun ASCs was significantly lower than most dead cells. The distribution of living cells in (A) was more uniform than (B), and the phenomenon of cell cluster could be observed in Fig.

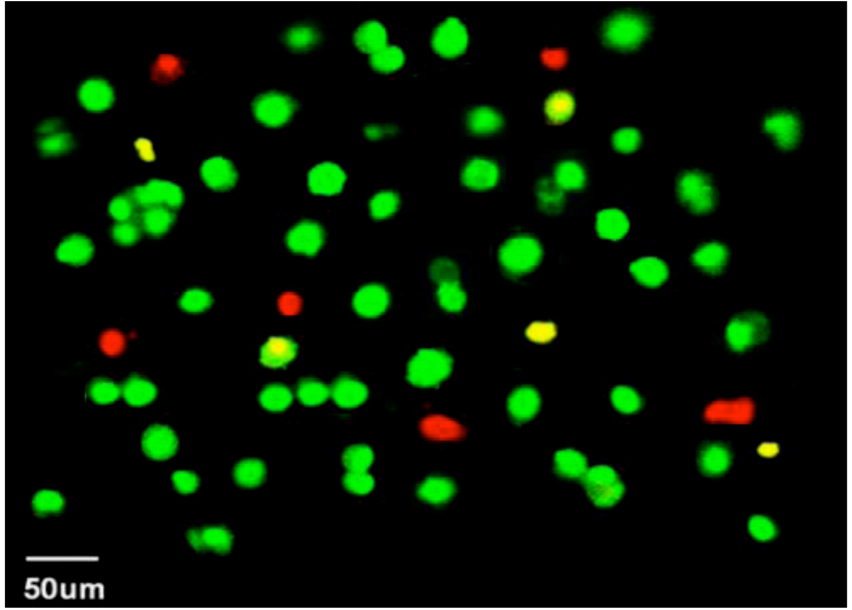

(A)
(3B) which may be caused by artificial factors of nonuniform mixture during the material preparation of electro spinning.

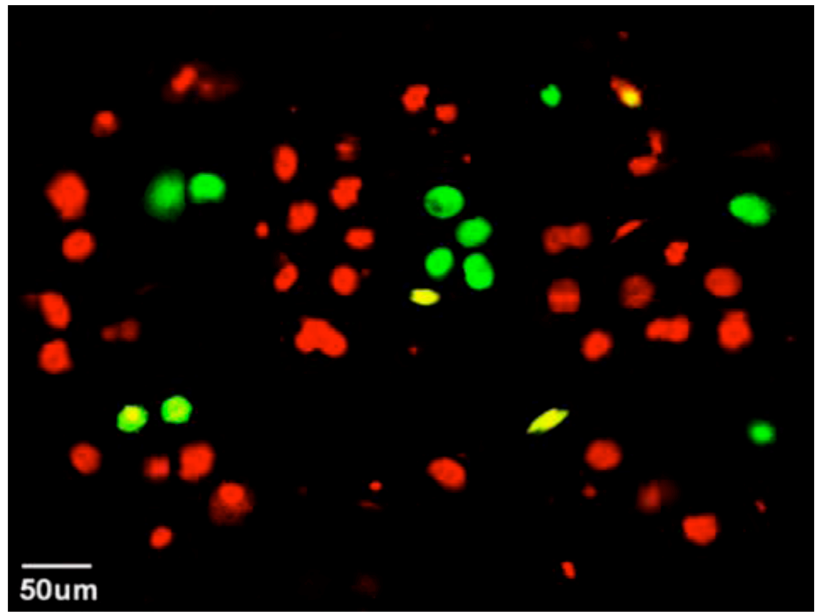

(B)

Fig. (3). Live/dead staining results: (A) ASCs micro integrated PVA nanofibers and (B) electro spun ASCs cells encapsulated within PVA. 


\subsection{ASCs Proliferation on Two Kinds of Scaffolds}

MTT assay can indirectly reflect the number of living cells. Early in culture $(1,2 \mathrm{~d})$ there was no significant difference of cell proliferation between integrated and electro spinning scaffolds, but in the mid-and late culture $(3,4,5,6,7 d)$ the difference became apparent. However, the OD value of the experimental group was always higher than the control group and was about two times of it at the seventh day (Fig. 4).

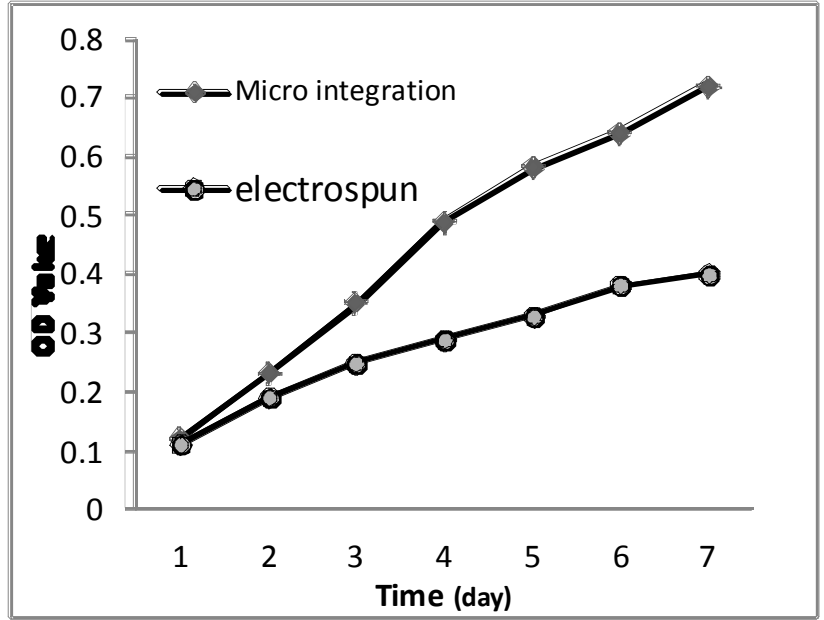

Fig. (4). The growth curve of cells of each group.

\subsection{Droplet Size Research}

In Fig. (5), the droplets size decreased with the increasing voltage and the reducing distance. The droplet size was 770um (standard deviation: $267 \mathrm{um}$ ) at the $16 \mathrm{KV}$ and $8 \mathrm{~cm}$, but it soon reduced to $72 \mathrm{um}$ (standard deviation: 15um) when the voltage increased to $25 \mathrm{KV}$. At the $24 \mathrm{KV}$ and $10 \mathrm{~cm}$, the droplet size was 98um (standard deviation: $18 \mathrm{um}$ ), and it reduced to 48um (standard deviation: 12um) with the distance reduced to $6 \mathrm{~cm}$ (Fig. 5A). Reducing the distance and increasing the voltage may effectively improve the electric field intensity, which increased the surface adsorption and activity, reduced the surface tension and accordingly decreased the viscous resistance of the atomization. However, the distance cannot be too small to affect the jetting efficiency.

The flow rate needs to match the applied voltage (Fig. 5B). With the large flow rate and small voltage, the cell suspension ejected from the top of the Taylor cone would reach the receiver scaffolds without been completely atomized, causing the too large droplet size. With the small flow rate and large voltage, however, the atomization efficiency would be reduced.

The finer the nozzle, the enhanced the electric field was. The charged collision increased the extent of droplet division significantly, so that the droplet size decreased (Fig. 5C). Through the above analysis, the droplets size can be effectively controlled by properly adjusting the parameters of electrosprays and a near-mono distribution of droplets can be generated with no larger than 50um (standard deviation: 15um), which has some significant improvement in resolution and distribution evenness of cells on the scaffolds. Furthermore, to fabricate regenerated tissues with normal function and phenotypic expression, it is desired that cells be evenly distributed along the scaffold structure [14].

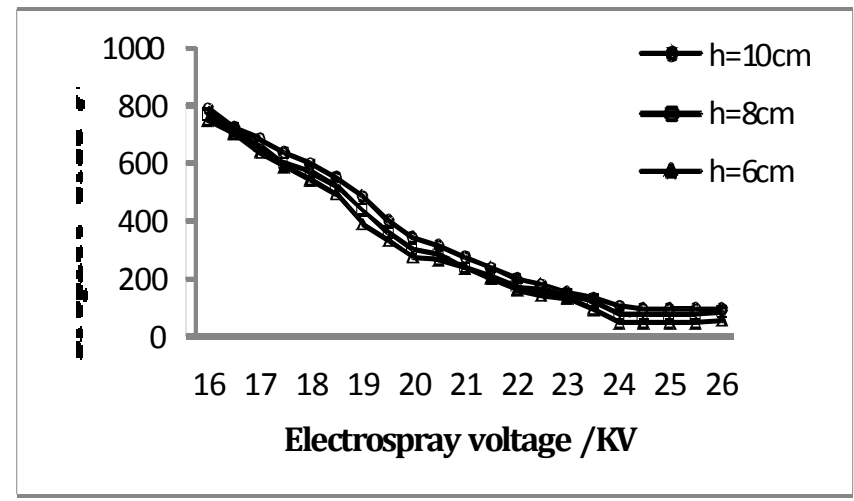

(A)

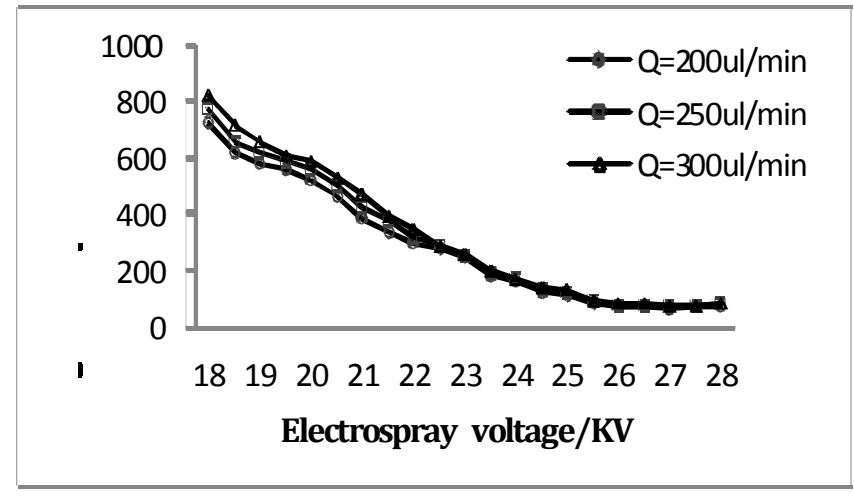

(B)

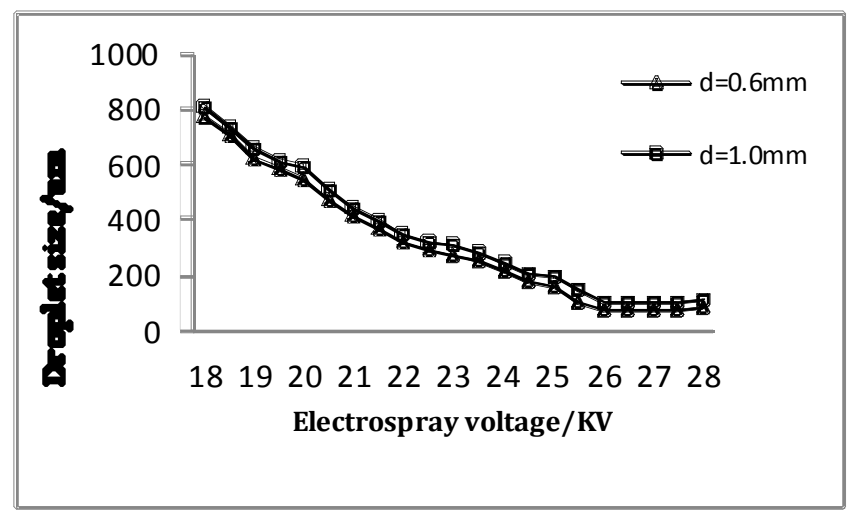

(C)

Fig. (5). Test results of droplet size in bio-electrospray cell suspension: (A) distance of the needle from the collecting plate, (B) flow rate and $(\mathbf{C})$ the inner diameter of the needle.

\section{CONCLUSION}

There are several approaches to reconstruct synthetic tissue and organs. However, in keeping with the demand for mimicking native microenvironments, advanced jet-based sciences have demonstrated the least number of steps (preand post-processing) required for directly forming threedimensional, multi-cellular, fully functional constructs [15]. Bio-electrosprays and cell electro spinning, which are very closely related, are two recently unearthed jet-based routes for directly engineering the living cells and organisms [16]. 
In this paper, the authors developed a micro integration system combining electro spinning and electro spraying techniques to directly deliver living cells into simultaneously fabricated scaffolds, which demonstrated a promising way to produce cell-containing scaffolds that is superior to the single electro spinning technique.

In addition, the effect of different parameters of bioelectro spraying (voltage, flow rate, distance and needle inner diameter) on droplet size of cell suspension was investigated. The droplets with a near-mono distribution $(<50$ um) were able to be generated to deposit a single living cell within a droplet under the appropriate parameters. The combination could be a promising approach for building high cell density scaffold with cells uniformly distributed in the structure. This method might find future use in the fabrication of high cell density elastic tissue mimetic, blood vessels or other cardiovascular tissues.

\section{CONFLICT OF INTEREST}

The authors confirm that this article content has no conflict of interest.

\section{ACKNOWLEDGEMENTS}

This study is partly supported by National Natural Science Foundation of China (No.51375292 \& No. 51475281), National Youth Foundation of China (51105239).

\section{REFERENCES}

[1] S. Sahoo, W.C. Lee, J.C.H. Goh, and S.L. Toh, "Bioelectrospraying: a potentially safe technique for delivering progenitor cells", Biotechnology and Bioengineering, vol. ED-11, pp. 690-698, 2011.

[2] A. Formhals, "Apparatus for producing artificial filaments from materials such as cellulose acetate”, US Patent, vol. 75, pp. 19341942, 2005.
[3] W. Li, C.T. Laurencin, E.J. Caterson, R.S. Tuan, and F.K. Ko, "Electrospun nanofibrous structure: a novel scaffold for tissue engineering", Biomedical Material Research, vol. 103, pp. 613634,2002 .

[4] M. Shin, O. Ishii, T. Sueda, and J.P. Vacanti, "Contractile cardiac grafts using a novel nanofibrous mesh", Biomaterials, vol. 3, pp. 3717-3740, 2004.

[5] J. J. Stankus, J. Guan, F. Kazuro, and W. R. Wagner, "Microintegrating smooth muscle cells into a biodegradable, elastomeric fiber matrix", Biometerials, vol. 3, pp. 735-744, 2006.

[6] H. Kempski, N. Austin, and A. Roe, "Pilot study to investigate the possibility of cytogenetic and physiological changes in bioelectrosprayed human lymphocyte cells", Regenerative Medicine, vol. 35, pp. 343-349, 2008.

[7] T. Boland, T. Xu, B. Damon and X. Cui, "Application of inkjet printing to tissue engineering", Biotechnology, vol. 125, pp. 19101917, 2006.

[8] N. Mongkoldhumrongkul, J. M. Flanagan, and S. N Jayasinghe, "Direct jetting approaches for handling stem cells", Biomedical materials, vol. 49, p. 1-8, 2009.

[9] S. N. Jayasinghe, P. A. M. Eagles, and A. N. Qureshi, "Electric field driven jetting: an emerging approach for processing living cells", Biotechnology, vol. 37, pp. 86-94, 2006.

[10] P. A. Eagles, A. N. Qureshi, and S.N. Jayasinghe, "Electrohydrodynamic jetting of mouse neuronal cells," Biochemistry, vol. ED-83, pp. 375-394, 2006.

[11] P. de Vos, S. Nicolai, and S. N. Jayasinghe, "Bio-electrospraying and Cell Electrospinning: Progress and Opportunities for Basic Biology and Clinical Sciences," Advanced Healthcare Materials, vol. 57, pp. 27-34, 2012

[12] S.N. Jayasinghe, P.A. Eagles, and A.N. Qureshi, "Electric field driven jetting: An emerging approach for processing living cells," Biotechnology, vol. 55, pp. 86-94, 2006.

[13] A.N. Qureshi, and P.A. Eagles, "Electrohydrodynamic jet processing: An advanced electric-field-driven jetting phenomenon for processing living cells," Small, vol. 11, pp. 216-219, 2006.

[14] R. Langer, "Tissue engineering," Molecular Therapy, vol. 64, pp. 12-15, 2001.

[15] S. N. Jayasinghe, "Biojets in regenerative biology and medicine," Materialstoday, vol. 14, pp. 202-211, 2011.

[16] S. N. Jayasinghe, S. Irvine, and J. R. McEwan, "Cell electrospinning highly concentrated cellular suspensions containing primary living organisms into cell-bearing threads and scaffolds," Nanomedicine, vol. ED-27, pp. 555-567, 2007.

\author{
Received: August 27, 2014 \\ Revised: November 21, 2014 \\ Accepted: December 19, 2014 \\ (C) Yunmin et al.; Licensee Bentham Open
}

This is an open access article licensed under the terms of the Creative Commons Attribution Non-Commercial License (http://creativecommons.org/licenses/ by-nc/4.0/) which permits unrestricted, non-commercial use, distribution and reproduction in any medium, provided the work is properly cited. 